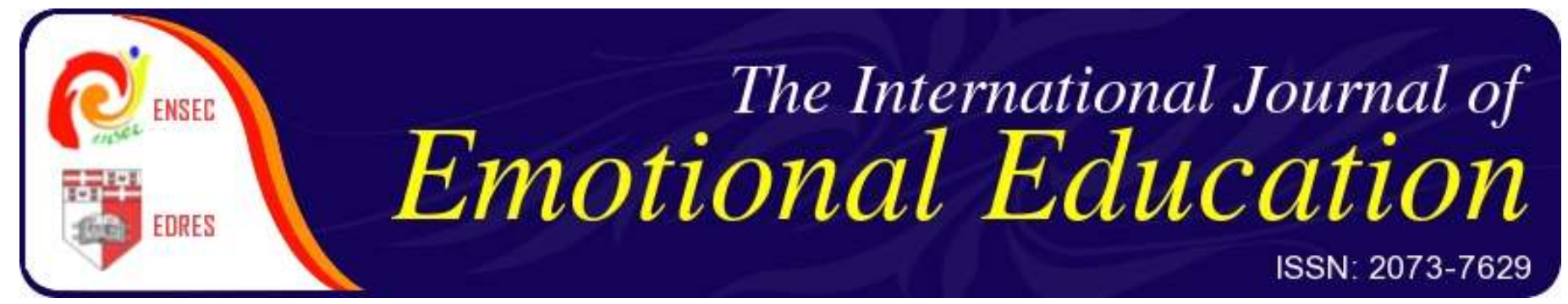

Volume 3, Number 1, April 2011 pp 30-47

www.enseceurope.org/journal

\title{
Promoting social-emotional learning in Chinese schools: A feasibility study of PATHS implementation in Hong Kong
}

\author{
Chi-Ming Kam ${ }^{11}$. ${ }^{\text {Lance Wai-lap Wong }}{ }^{\mathrm{a},}$ Kennis Mei-sze Fung ${ }^{\mathrm{a}}$ \\ ${ }^{a}$ Department of Psychology, University of Hong Kong, Hong Kong.
}

\begin{abstract}
This paper describes a pilot study of a reduced version of the PATHS Curriculum, a USdeveloped evidence-based SEL program, among schools in Hong Kong SAR (China). Three hundred and sixteen 12th grade students in three elementary schools participated in the study. A limited number of first grade PATHS lessons were adapted and translated into Chinese. Twelve teachers learned and adopted these lessons in their teaching. Students in these classrooms learned about different emotions and practiced self-control. The intervention lasted four months. After the intervention, students showed improvement in emotion understanding, emotion regulation and prosocial behavior. No change was observed in the level of children's problem behaviors. Over $65 \%$ of the teachers reported a high degree of satisfaction and willingness to adopt the intervention. The effects of the intervention varied among schools, with variations in the level of intervention and principal support, but not in the quality of implementation. Discussion is focused on the factors that could shape the adoption and implementation of SEL programs, especially the role of the difference in school systems between Hong Kong and the United States.
\end{abstract}

Keywords: PATHS, social emotional learning, universal intervention, Chinese schools, social and emotional development

\section{Introduction}

In his 1995 bestseller Emotional Intelligence, Daniel Goleman popularized the concept of emotional intelligence to a global audience. With case illustrations and research findings from diverse fields, Goleman eloquently demonstrated the importance of Emotional Quotient (EQ) in our daily lives (Goleman 1995). Around the same time, another best-selling book, The Multiple Intelligences by Howard Gardner, also stimulated a lot of interests worldwide in the role of personal and social intelligence (Gardner 1993). In the

\footnotetext{
${ }^{1}$ Corresponding author. Email address: cmkam@hkucc.hku.hk
} 
past two decades, an expanding volume of research has firmly established the role of social and emotional competence in healthy human development. The process by which one builds the capacity to recognize and manage emotions, resolve problems effectively, and establish positive relationships with others is termed social emotional learning (SEL) (Elias et al. 1997; Payton et al. 2000; Zins and Elias 2006). Both educators and mental health professionals recognize the importance of fostering social and emotional learning among children and adolescents (Catalano et al. 2004; Weare 2004; Zins and Elias 2006; Center for Mental Health in Schools at UCLA 2008).

Research shows that SEL has positive effects on academic performance, benefits physical health, improves citizenship, is demanded by employers, and is essential for lifelong success. It also reduces the risk of maladjustment, failed relationships, interpersonal violence, substance abuse, and unhappiness (Greenberg, Domitrovich, and Bumbarger, 2001; Zins et al. 2004; Schucksmith et al. 2007; Tennant et al. 2007; Diekstra 2008a, 2008b; Payton et al. 2008; Durlak et al. 2011). There is now increasingly a common understanding that social and emotional learning can be taught, by parents at home and by teachers in schools (Gottman and DeClaire 1998; Elias et al.1997; CASEL 2003; Greenberg et al. 2003). A growing number of programs, strategies, and techniques are available for promoting healthy development and preventing negative outcomes, and a stronger empirical base has emerged in the SEL field (Weare and Gray, 2003; Payton et al. 2008; Weare 2010).

The United States remains the hub for the development and dissemination of SEL programs. The recent Academic Social and Emotional Learning Act (H.R. 4223) authorizes the U.S. Department of Education to establish a national SEL training center, and provide grants to support evidence-based SEL programs and evaluate their success (DeAngelis 2010). In the UK, the Social and Emotional Aspects of Learning (SEAL) program disseminated by the U.K. Department of Education is part of the National $\mathrm{S}$ trategies in Britain for the promotion of social and emotional learning in schools. (Department for Education 2010). There are also similar SEL movements in other parts of Europe, such as the dissemination of the Life Skills and Skills for Life programs in the Netherland, Canada, Australia (Marcelion-Botin-Foundation 2008) and parts of Asia (eg. Ministry of Education, Singapore 2010). The present study examined an attempt to introduce the PATHS Curriculum, a SEL program, into schools in Hong Kong SAR (China).

In his book Educating Minds and Hearts, Jonathan Cohen (1999) rightfully pointed out that "school life always profoundly affects the social and emotional lives of students and educators. Teacher-student and peer relations, our pedagogic methods, and the learning process shape students' experience of themselves and others ... In any case, school and family life are the two major social arenas that shape and color children's social and emotional worlds." (Cohen 1999). Other than providing literacy and academic training, school is also a place where SEL should be promoted and taught (Greenberg, Domitrovich, and Bumbarger 2001; Zins 2001; Green et al. 2005; Zins and Elias 2006). In recent years, there has been emerging evidence linking SEL with academic achievement. Students with advanced social and emotional learning are also likely to excel in 
their academic achievement (Zins et al. 2001, 2007). Some SEL programs are designed to provide systematic training for students, and SEL lessons are incorporated into the formal curriculum. Many of these programs are universal prevention programs that aim at enhancing competence and strengthening resilience for all students (Albee and Gullotta 1997; Catalano et al. 1999; Centre for Substance Abuse Prevention 1999; Greenberg, Domitrovich, and Bumbarger 2001; Adi et al. 2007a, 2007b).

\section{The SEL situation in Hong Kong}

Hong Kong is a densely populated and high-pace metropolitan city, with the majority of the population being ethnic Chinese. Epidemiological findings suggested that Hong Kong Chinese children face the same kind of developmental and mental health challenges as those faced by children in the West (Leung et al. 2008). Eisenberg and colleagues found that Chinese and U.S. children have similar patterns of effortful control and emotionality (Zhou et al. 2004; Eisenberg et al. 2007). On the other hand, in studies on cultural variation in emotional expression, it was found that Chinese and other Asians tended to dampen their emotional expressions in the interests of maintaining group harmony (Tsai et al. 2002). Chen, in a series of research examining Chinese children's social development, found that, similar to children in the West, both aggressive and withdrawn Chinese children were at-risk for social isolation and peer rejection (Chen et al. 2002, 2005). This is also generally true for Chinese children in Hong Kong (Chang et al. 2005; Duong et al. 2009).

Recently, there has been an increase in the rate of mental health problems, such as abuse of psychotropic substances, suicide and school violence, among youths in Hong Kong (Sun and Shek 2010). Because psychiatric conditions are strongly stigmatized among the Chinese, some local child psychiatrists argue that there is a strong need for primary prevention in Hong Kong (Lai 2000). Universal mental health promotion programs, such as school-based SEL programs, would be "highly desirable" and in need in Hong Kong.

Chinese societies, including that in Hong Kong, are considered Confucian heritage cultures (CHCs) (Ho 1991). The teaching context in CHC schools are characterized as "unvarying and expository, taking place in what seem to be highly authoritarian classrooms, where the main thrust of teaching and learning is focused on the preparation for external examinations ...” (Biggs 1997, p.147). Traditionally, schools in Hong Kong pay less attention to students' personal development, in comparison to time spent on academic training.

The situation started to change about ten years ago, when the government's Education Bureau (EDB) launched a comprehensive overhaul of the educational system in Hong Kong. Whole person development and life-long learning have become the central curricular objectives for all the schools in the territory (Education Commission 2000). Personal, social and humanities education (PSHE), and moral and civic education (MCE), have become two core areas of education in schools (Curriculum Development Council 2001). Schools are urged by the EDB to see the all round development of their students as their major educational aim. It 
becomes more likely that schools will welcome the incorporation of SEL and primary prevention programs in their curricula.

\section{The Promoting Alternative THinking Strategies (PATHS) Curriculum}

The PATHS Curriculum was developed by Greenberg and Kusché in the ninetes. (Greenberg and Kusché 1993). It is a school-based SEL program that promotes emotion understanding, emotion regulation and problem solving skills. The PATHS Curriculum model draws on basic developmental research, suggesting that the development of more complex and accurate plans and strategies (social-cognition) regarding interpersonal problems has a major influence on children's social behaviors. If children misidentify their own feelings or those of others, they are likely to generate maladaptive solutions to a problem. In addition, the child's motivation for communicating his or her feelings and problem solving in interpersonal contexts will also be greatly affected by the modeling and reinforcement of adults and peers. The design of PATHS is based on the ABCD (affective-behavioral-cognitive-dynamic) model of development (Greenberg, Kusché, and Speltz 1991; Greenberg and Kusché 1993), which places primary importance on the developmental integration of affect, behavior, and cognitive understanding as they relate to social and emotional competence. A basic premise is that a child's coping, as reflected in his or her behavior and internal regulation, is a function of emotional awareness, affective-cognitive control and behavioral skills, and socialcognitive understanding. The PATHS Curriculum model synthesizes the domains of self-control, emotional awareness and understanding, and social problem solving to increase social and emotional competence.

PATHS is a multi-year curriculum characterized by its developmental emphasis. It is implemented and taught in schools by trained teachers. PATHS is also a universal intervention that is offered to all the students in a school. Besides directly teaching children social and emotional skills, the program also emphasizes the importance of creating a supportive classroom and school climate for promoting SEL. In the lessons for young children, more focus is put on emotion understanding and impulse control. For older children, there is an emphasis on peer relationship and social problem solving.

The PATHS Curriculum is an evidence-supported school-based prevention program that has been trialed in well designed experiments and used in regular and special education classrooms. PATHS has been shown to reduce externalizing and internalizing problem behaviors, peer aggression, conduct problems, hyperactivity and frustration tolerance, and enhance emotion regulation and planning (Greenberg and Kusché 1993; Greenberg and Kusché 1996; Greenberg and Kusché 1997). It has also been translated into various languages and used in a variety of schools for normal, deaf, and other special needs children in numerous countries across the world (Penn State Prevention Research Center 2010).

The present study examined a pilot implementation of a limited number of lessons drawn from the PATHS Curriculum among schools in Hong Kong. 


\section{Methodology}

\section{Participants}

Three hundred and sixteen first grade students participated in the study (164 males; 152 females). They were students from three elementary schools located in three different regions in Hong Kong. One school is located in Tin Shui Wai $(n=139)$, the northwest part of Hong Kong, where there is high concentration of newly immigrated and low SES families. A second school enrolls students from families living in Kwun Tong ( $\mathrm{n}=99$ ), an old urban district with a high proportion of families living in low cost public housing estates. On the contrary, the third school is a subsidized school operating in Kowloon Tong ( $\mathrm{n}=78$ ), a well-off district in the city. Students in this school come mostly from relatively high SES families.

\section{Research design}

Before contacting the three participating schools, we contacted a few other schools and invited them to participate in the study. These schools eventually declined to join because of other commitments. In this pilot trial, a single-group pretest-posttest design was adopted. All the participating schools were in the intervention condition and there was no control-condition school. First grade teachers in the three schools were trained and they delivered the intervention in their classrooms. The intervention lasted for approximately four months. Measures of students' social emotional learning and behavior problems were taken before and after the implementation of PATHS. Changes in the outcomes were calculated and tested. Throughout the intervention, a PATHS coordinator paid weekly visit to the schools, to render technical support to the teachers, and observed the PATHS lessons. The PATHS coordinator provided monthly rating of PATHS implementation and an overall rating of principal support for the PATHS program. At the end of the intervention, teachers were asked to rate the effectiveness of the PATHS program and to provide their opinions on the adaptation of PATHS in local schools.

\section{Intervention}

Through contacts with individual schools, first grade teachers in three elementary schools from three different districts were recruited to participate in the project. In each of the schools, there were 4 first grade classrooms participating in the study.

Lessons drawn from the PATHS Curriculum (volumes 1 and 2) were translated into Chinese. Due to time constraints, of the 32 lessons in the original version, about 16 lessons were utilized. These 16 lessons deal with the more basic emotions and the topic of self control. All lessons were drawn from the Feelings Unit and only four of the twenty-five feeling states (happy, angry, sad and fearful) were taught. Each lesson lasted about 35 minutes and activities included group discussion, role-playing, art activities, stories, and educational games. 
All teachers received the same two-day training by a PATHS trainer, who has abundant experience in implementing PATHS and training school teachers in Australia. The training of school teachers covered topics such as the general theory behind the PATHS Curriculum such as the ABCD model, and the adaptation of PATHS lessons. Teachers were encouraged to think about daily examples in their classrooms or in the playground that were relevant to the teaching of the PATHS concepts. These examples would facilitate children's identification and internalization of the knowledge and values. They would also help teachers tailor their lessons to fit the developmental, behavioral, and emotional needs of their students. In the training workshop, teachers also had the chance to try out some PATHS activities and had discussions on the use of PATHS lessons in their classrooms. When the teachers started teaching PATHS, the PATHS coordinator visited the school weekly to provide technical support to each individual teacher. During some of these visits, the PATHS coordinator also observed the teachers' teaching PATHS, and the coordinator rated the teachers' quality of implementation. The coordinator also rated the extent the teachers generalized PATHS concepts throughout the school day, and whether they promoted students' discussion of feelings and the use of problem solving skills in a variety of situations, both inside and outside the classroom.

In this pilot trial, very little "control" was imposed on how schools were implementing the program. Basically, all teachers used the basic emotion lessons, the "Control Signal Poster", as well as the "PATHS Kids of the Day". There were variations in the number of lessons taught in different schools. The frequency and duration of the intervention were all below that suggested by the PATHS trainer manual. PATHS is supposed to be a whole year curriculum but the present trial lasted only four months. It is suggested that PATHS should be taught for 20-30 minutes a day, three to five days a week, but PATHS lessons were taught only once a week in the three schools in this trial. Teachers did not use any social problem solving lessons. Different schools adopted different numbers of lessons (8 to 16 lessons), and hence the level of the intervention varied among schools.

Schools in Hong Kong have to work within the boundary of the "central" curriculum laid down by the government. Thus, teachers needed to find niches in the curriculum to incorporate the PATHS lessons. One of the schools set aside its civic and moral education lessons for the teaching of PATHS; another used its personal growth education lessons, while the third school had more flexibility in designing and teaching its own curriculum. It designed and implemented its own version of "EQ lessons", and the PATHS lessons were incorporated into this curriculum.

\section{Measures}

Child Behavior Questionnaire (CBQ-Teacher). This measure is a teacher rating scale developed for the Penn State REDI project measuring children's adaptation in school. A factor analysis of the CBQ-Teacher was conducted on the present sample. Four correlated factors were found and hence four subscales were formed, namely Emotion regulation skills (10 items, e.g. "Stops and calms down when frustrated or upset", 
alpha $=0.93$ ); Prosocial behaviors (5 items, e.g. "Invites others to play", alpha $=0.83$ ); Externalizing behaviors ( 8 items, e.g. "Fights with other children“, alpha $=0.90)$ and Internalizing behaviors ( 3 items, e.g. "Feelings are easily hurt", alpha $=0.64)$.

Pre-Intervention Behavioral Risk Score. The pre-intervention behavioral risk score of each child was computed by combining and averaging the scores of the four behavioral scales of the Child Behavior Questionnaire. Such a score represents the frequency of children's problem behaviors and the lack of social and emotional competence before the intervention.

The Assessment of Children's Emotions Scales (ACES; Schultz et al. 2001) was administered to assess the children's emotional expression knowledge and to determine whether they exhibited any anger bias. In this task, interviewers presented children with twelve photographs of elementary-aged children posing facial expressions. The images used in this study were a subset of the twenty-six photographs from the original version of the measure. These included two validated expressions for each of the four basic feelings (happy, sad, scared, and mad). For the purpose of eliciting children's emotional biases, an additional set of four expressionless faces were included. The anger bias score is the percentage of time children incorrectly identified the faces as displaying anger. After presenting a photograph, the interviewer asked the child, "Does s/he feel happy, sad, mad, scared, or no feeling?" The emotion accuracy score reflects the number of items a child answered correctly (alpha $=.59)$.

Emotion Recognition Questionnaire (ERQ). The Emotion Recognition Questionnaire (Camras et al. 1988) assesses young children's emotion knowledge. Sixteen 2-sentence situations were presented covering the range of emotions (happy, sad, angry, and afraid). Interviewers read out short stories that depicted situations in which children encounter emotion-laden events. The participating child was asked to identify the emotion the child in the story would experience. The number of correct answers was tallied and scored into a total ERQ score.

\section{Mode and level of implementation}

Similar to schools in other parts of China, the class teachers in Hong Kong are responsible for the personal needs of students in their classes. These teachers usually teach major subjects in class, and they are also responsible for taking care of the students in their classes (Eisenberg et al. 2007). In the present study, the class teachers implemented the PATHS in two of the schools, while in the other school, the SGT taught PATHS to all the first grade classes. The SGT is a school teacher responsible for the counseling and personal growth of students in the whole school. He/she usually takes up the personal growth education lessons, which is approximately once a week. Thus, for this school, the teaching of PATHS was less frequent. 


\section{Implementation Quality}

The PATHS coordinator observed PATHS lessons and rated the quality of teachers' implementation of PATHS. Overall, there were six rating scales in the PATHS coordinator's ratings. Three of these ratings were particularly relevant to the evaluation of the extent the teachers were using PATHS -- the first rated the fidelity of their implementation, the second rated the degree by which the teachers were able to generalize the PATHS lessons to other settings in the school, and the third rated the openness of the teachers to consultation with the PATHS coordinator. These three ratings were combined to form a scale measuring the quality of PATHS implementation.

\section{Teachers' Acceptance of PATHS and Principal Support}

After the PATHS trial, the teachers were asked to complete a survey that assessed seven areas regarding their rating of the various components of PATHS and the training workshop. These were the PATHS Kid of the Day and Complimenting; Self Control Signal Poster and Self Control; The Feeling Lessons and Feeling Faces; Communication with Parents; the PATHS impact on teacher teaching; Quality of Support and Training Workshop; and Overall rating on PATHS implementation. Teachers rated the program on a scale from one to five.

The PATHS coordinator and her supervisor were asked to independently rate principal support for the implementation of PATHS. Two measures were used in the study:, namely the Quality of principal support for PATHS, and the Quality of support for the PATHS technical assistance team. For both measures, a scale from 1 (Not supportive at all) to 4 (Very supportive) was used. The first rating measured the extent principals showed support in general for the intervention. It is based on the impression the PATHS coordinator and her supervisor got from their personal interactions with the principals and their observations of the support teachers got from their principals. A high rating would indicate that the principal saw PATHS as part of the central mission of the school, supported staff effectively, spoke positively about PATHS with staff, and had PATHS materials visible and used in the office. A low rating would mean that the principal did not speak positively about PATHS with staff, only occasionally showed support for PATHS in faculty and staff discussions, and did not see success of PATHS and social-emotional learning as central to the school's mission. The second measure was more specific and represented the relationship the PATHS coordinator and her team had with the principal. A low score would include not welcoming the coordinator or assisting the coordinator in becoming part of the school culture. A high score was given to a principal who developed a true collaboration with the technical assistance team and treated the PATHS coordinator as an essential component for building success. 


\section{Results}

Thirteen students "dropped out" in the post-intervention measurement. Their data were not included in the pre-post intervention comparison and subsequent analyses. On the other hand, there was no attrition in the teacher sample.

\section{Changes in Students' Social and Emotional Competence}

In assessing the effects of our intervention, the changes in the level of outcome variables from preintervention to post-intervention were examined. Analysis of covariance, with children's pre-intervention behavioral risk score as the covariate, was applied to the pre-post difference scores in the outcomes. In essence, we obtained adjusted estimates of the outcome difference scores, taking out the initial differences in children's behavioral risk. Effect sizes for these effects were also calculated and are shown in Table 1. The children showed increases in their emotion understanding, both for reading emotional faces (ACES Total) and for understanding emotion-eliciting situations (ERQ Total). They also showed increases in their emotion regulation and prosocial behaviors, as measured by their teachers' CBQ ratings. The teachers reported no increase in children's internalizing behaviors, but they reported an increase in children's externalizing behaviors.

Table I. Pre-Post Intervention Differences on Outcome Variables

\begin{tabular}{|l|c|c|c|c|}
\hline & $\begin{array}{c}\text { Adjusted Mean } \\
\text { Difference } \\
\text { (Standard Error) }\end{array}$ & $\begin{array}{c}\text { Pre Mean } \\
\text { Score }\end{array}$ & $\begin{array}{c}\text { Post Mean } \\
\text { Score }\end{array}$ & $\begin{array}{c}\text { Partial Eta } \\
\text { Square }\end{array}$ \\
\hline $\begin{array}{l}\text { 1. Emotion Regulation (CBQ) (n } \\
=289)\end{array}$ & $0.14(.03)^{*}$ & 3.65 & 3.79 & .05 \\
\hline $\begin{array}{l}\text { 2. Pro-social Behaviors (CBQ) (n } \\
=291)\end{array}$ & $0.11(.04)^{*}$ & 4.30 & 4.41 & .03 \\
\hline $\begin{array}{l}\text { 3. Externalizing Problems (CBQ) } \\
(\mathrm{n}=293)\end{array}$ & $0.10(.03)^{*}$ & 1.85 & 1.95 & .04 \\
\hline $\begin{array}{l}\text { 4. Internalizing Problems (CBQ) } \\
(\mathrm{n}=295)\end{array}$ & $-0.00(.04)$ & 2.35 & 2.35 & .00 \\
\hline 5. ACES Total (n=279) & $1.51(.14)^{*}$ & 8.51 & 10.01 & .31 \\
\hline 6. ERQ Total $(\mathrm{n}=280)$ & $0.93(.15)^{*}$ & 12.53 & 13.46 & .11 \\
\hline
\end{tabular}

Mean differences are based on subtracting pre-score from post-score; Adjusted Mean Differences" are adjusted by the pre-intervention risk score;

$* \mathrm{p}<0.005$

\section{Differences among the Three Schools}

To understand the different effects of the intervention on children's behaviors in the three schools, comparisons in the outcomes among the schools were conducted. Table 2 reports the levels of preintervention behavioral risk and the pre-post intervention differences in outcomes among the three schools. 
First, the pre-intervention behavioral risk scores were compared. The children in school 2 had significantly higher behavioral risk before the intervention, compared to children in the two other schools. This may be due to the fact that there were a higher proportion of students with special educational needs in two of the classrooms in this school. Children in these classrooms might have more problem behaviors initially when they entered the intervention We conducted additional analyses on the CBQ outcomes, taking out children in these two classrooms in school 2. The results were similar, except that there was no longer an increase in externalizing behaviors. In school 2, there was an increase in students' externalizing behaviors over the intervention period. No such increase was found in the other two schools. There were no differences among the three schools in students' change in emotion regulation and emotion understanding.

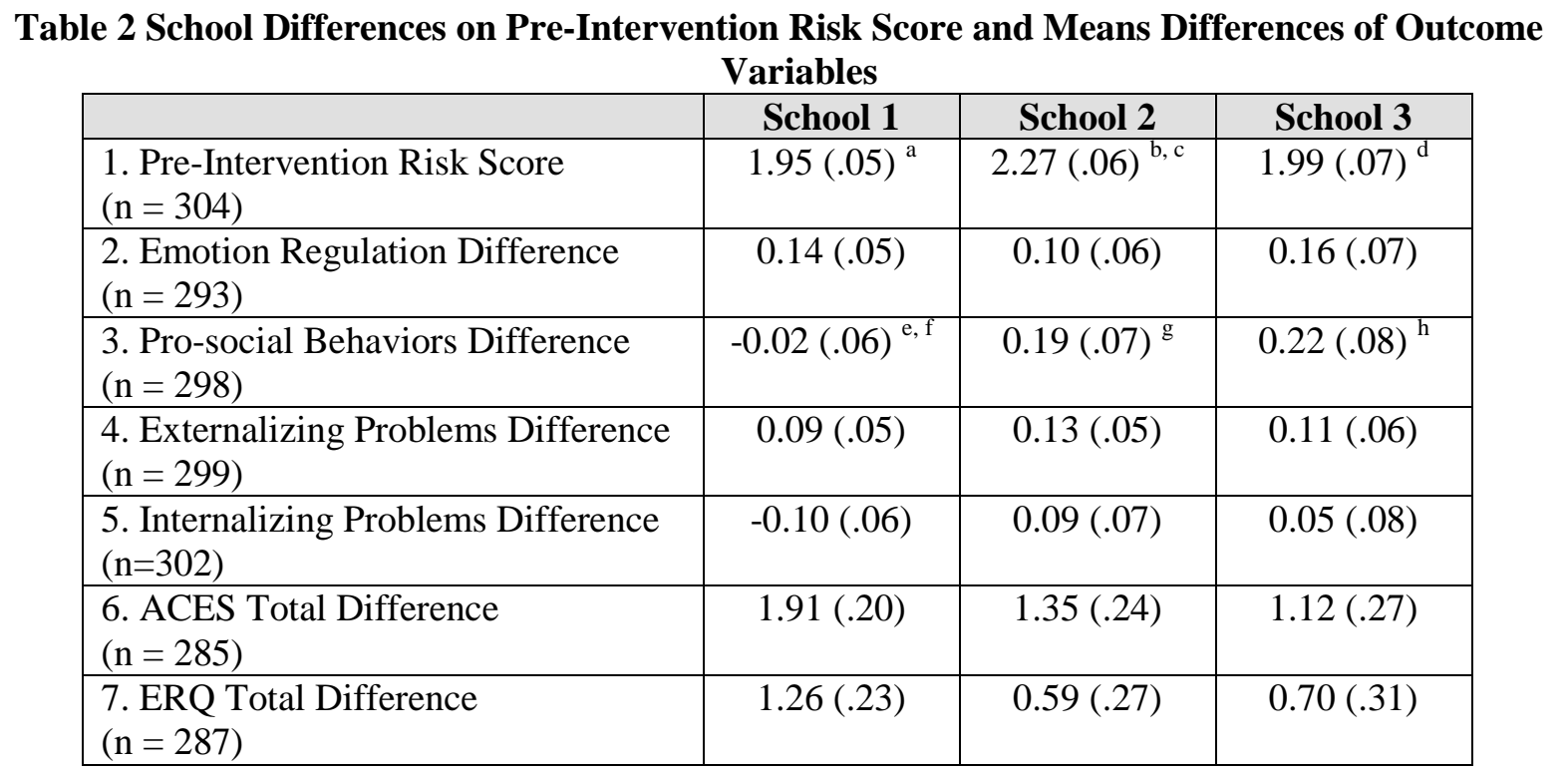

Numbers in the bracket are the standard errors; means with the pairs of superscripts $(\mathrm{a}, \mathrm{b}),(\mathrm{c}, \mathrm{d}),(\mathrm{e}, \mathrm{f}),(\mathrm{g}, \mathrm{h})$ denote significant pair-wise differences.

\section{Program Implementation Quality and Principal Support}

The quality of implementation did not vary much among or within the three schools [School 1: mean $=2.75$, range (2.67 to 2.67 ); school 2 : mean $=2.83$, range ( 2.3 to 3$)$; school 3 : mean $=2.67$, range ( 2.3 to 3)]. To examine the relationship between the quality of program implementation and students' gains in the outcomes, the outcome difference scores were regressed on the implementation score. Program implementation quality did not predict the size of the difference scores.

The support from the school administration for the implementation of PATHS differed among the three schools. The principal in school 2 was the least supportive. The SGT told us that the principal rarely talked to her about the PATHS lessons she taught in the school. He also only stopped by briefly in the parent seminar we organised. In the other two schools, the principals showed moderate to high support to the PATHS program. Principals in both schools took time to talk to our team and showed support to the 
programming. The principal in school 1 stressed that schools need more interventions like the PATHS Curriculum.

\section{Teacher Ratings of PATHS}

Table 3 tabulates the participating teachers' overall impression of the PATHS Curriculum after they implemented it for several months. For the individual components in PATHS, the majority of teachers felt that the PATHS lessons and activities benefited their students. Overwhelmingly, teachers liked the PATHS Kid of the Day (Complimenting). A majority of teachers felt that the technical support they received from our PATHS coordinator was good, while quite a number of teachers felt that the PATHS Curriculum fit with their own teaching styles. For the impact of PATHS, the highest rating from the teachers went to the improvement of classroom climate and the improvement of students' social competence. A high percentage of teachers felt that PATHS improved their communication about feelings with their students.

Table 3 Teachers' Views on PATHS

\begin{tabular}{|l|c|c|}
\hline & Mean rating & $\begin{array}{c}\text { Percentage of teachers } \\
\text { rating 4 or above }\end{array}$ \\
\hline PATHS Components & & $93.3 \%$ \\
\hline 1. Complimenting & 4.43 & $33.3 \%$ \\
\hline 2. Self-Control & 3.72 & $66.7 \%$ \\
\hline 3. Feeling Lessons & 3.95 & $49.3 \%$ \\
\hline 4. Communications with Parents & 3.32 & $64.2 \%$ \\
\hline Training, Implementation and Support & 3.64 & $73.3 \%$ \\
\hline 5. Quality of the Training Workshop & 3.93 & $73.3 \%$ \\
\hline 6. Quality of Support received & 3.87 & $73.3 \%$ \\
\hline 7. Encouragement from Principal & 4.13 & $86.7 \%$ \\
\hline 8. Fit between PATHS and teaching style & 4.07 & $80 \%$ \\
\hline Perceived PATHS Impacts & 4.00 & $80 \%$ \\
\hline $\begin{array}{l}\text { 9. Improvement in communications about } \\
\text { feelings with students }\end{array}$ & 3.87 & $60 \%$ \\
\hline $\begin{array}{l}\text { 10. Improvement in discussion of problems } \\
\text { with students }\end{array}$ & 4.10 & $66.7 \%$ \\
\hline $\begin{array}{l}\text { 11. Improvement in proactive classroom } \\
\text { management }\end{array}$ & 4.10 & \\
\hline 12. Improvement in Classroom Climate & & \\
\hline $\begin{array}{l}\text { 13. Improvement of Students' Social } \\
\text { Competence }\end{array}$ & & \\
\hline
\end{tabular}

\section{Discussion}

Even though the present implementation of the PATHS lessons was brief and fragmented, we saw some possible positive effects of the program on children's emotional understanding and social competence. The lack of a comparison group in the study does not allow us to draw definite conclusions from our investigation, but we did find improvements in children's recognition of emotional expression and 
understanding of emotion-eliciting events. We also saw an increase in children's prosocial behaviors. We did not find, however, any effect on the children's problem behaviors. The Control Signal poster, which was designed for teaching self-control, was used in only one of the schools, but self-control lessons were not implemented, and thus the teachers placed no emphasis on self-control training. Thus, we did not expect to find an effect on children's self-regulatory behaviors.

Differences in the outcomes were found among the three schools. This was partly due to the initial difference in risk levels among the students in the three schools, which are located in three different districts in Hong Kong. The families residing in the three districts were markedly different in SES and resources. Hence, children entering these schools also differed in their behavioral risks. In addition, among the three schools, we found a great difference in the degree of implementation of PATHS and in the support school principals and teachers gave to the program.

There were differences in the degree of implementation (i.e. number and types of lessons) as well. In one of the schools, one guidance teacher delivered all the classes, which is not a recommended model of implementation for PATHS. This is because a guidance counselor is not present in the classroom during the rest of the school day and thus cannot reinforce and generalize the skills that are taught. No previous trials have used such a model and data here indicate that this would not be recommended for future interventions in the Hong Kong context. In translational research like this one, we need to pay attention not just to cultural difference, but also to the difference in the intervention delivery system (Payne, Gottfredson, and Gottfredson 2006).

Previous studies on the need of cultural sensitivity in the development of prevention programs (e.g. Kumpfer et al. 2002; Castro, Barrera, and Martinez 2004) focused on ethnic differences rather than crosscultural or cross-national differences. Even though some research suggested that Chinese kids are different in their emotional responses (e.g. they are less aggressive and less expressive both verbally and emotionally (Yik 2010), and we did encounter some difficulties (e.g. language difference) in translating concepts from US to Chinese, there were not too many difficulties in getting the main message across in training sessions with teachers. From the feedback from the participating teachers, we saw that SEL can be taught in Chinese classrooms, using the same design and content.

The lesson we learned in this pilot study is that we should start introducing SEL in kindergarten classes. In Hong Kong, the kindergartens operate more like the preschools in the U.S. The kindergarten lessons look more like the preschool group times, and the kindergarten teachers are both teachers and child care workers. The curriculum in the kindergarten is more flexible than that in primary and secondary schools, and thus more amenable to the introduction of SEL curricula, like the PATHS Curriculum. Besides, there is always a call for earlier implementation of SEL programs. The Preschool PATHS curriculum is designed specially for preschoolers. There is now some evidence that SEL programs work well in preschool settings (Bierman et al. 2008). 
Finally our results need to be viewed in the limitations of the present study. The greatest limitation was the lack of comparison or control school. As such, the students' gains in emotion skills cannot be adequately accounted for by our intervention. The gains can well be explained by their "natural" developmental progression in the 4- month period in which the intervention was implemented. Besides, because of the lack of comparison, it is difficult for us to interpret the increase in teacher-rated externalizing behaviors after the intervention. From our experience in schools, we know that as teachers become more familiar with their students, they often rate more problem behaviors. Further, as teachers who taught the PATHS lessons were also those who rated students' behaviors pre- and post-intervention, their knowledge that children received intervention might influenced their report of changes in students' behaviors.

This pilot study was meant to be set up as a feasibility study of the implementation of an SEL program in local Hong Kong schools. Yet, it was a very short and abbreviated trial -- about 4 months. As a matter of fact, the PATHS curriculum was not implemented as it should have been (PATHS instructor manual), and thus we did not expect the same kind of gains in students' social and emotional competence and the reduction of problem behaviors we saw in other trials of PATHS. Besides, we had very little control over what teachers or schools did when they were implementing PATHS. The situation we faced is somewhat similar to the one we had when we conducted an effectiveness trial of PATHS several years ago (Kam, Greenberg and Walls 2003). In fact, it is worse than that as teachers actually took the PATHS lessons and adapted it substantially so that these lessons could fit into the routines of their school.

\section{Note}

This work was supported by University of Hong Kong University Research Committee Seed Funding Programme for Basic Research 200611159220. Appreciation is expressed to parents, principals, teachers and students who participated in and supported this research.

\section{References}

Adi, Y., Killoran, A., Janmohamed, K., and Stewart-Brown, S. 2007a Systematic review of the effectiveness of interventions to promote mental wellbeing in primary schools: Universal approaches which do not focus on violence or bullying. London: National Institute for Clinical Excellence.

Adi, Y., Schrader McMillan, A., Kiloran, A. and Stewart-Brown, S. 2007b. Systematic review of the effectiveness of interventions to promote mental wellbeing in primary schools: Universal Approaches with focus on prevention of violence and bullying. London: National Institute for Clinical Excellence.

Albee, G. W., and Gullotta, T. P. 1997. Primary prevention works. Thousand Oaks: SAGE Publications, Inc. Bierman, K. L., Domitrovich, C. E., Nix, R. L., Gest, S. D., Welsh, J. A., Greenberg, M. T., Blair, C., Nelson, K. E., and Gill, S. 2008. Promoting academic and social-emotional school readiness: The 
Head Start REDI Program. Child Development,79, 1802-1817.

Biggs, J. B. 1997. Learning, schooling, and socialization: A Chinese solution to a Western problem. In S. Lau (Ed.), Growing up the Chinese way (pp. 148-167). Hong Kong: The Chinese University Press.

Camras, L. A., Ribordy, S., Hill, J., Martino, S., Spaccarelli, S., and Stefani, R. 1988. Recognition and posing of emotional expressions by abused children and their mothers. Developmental Psychology, 24, 776781.

Castro, F. G., Barrera, M., and Martinez, C. R. 2004. The cultural adaptation of prevention interventions: Resolving tensions between fidelity and fit. Prevention Science, 5, 41-46.

Catalano, R. F., Berglund, M. L., Ryan, J. A. M., Lonczak, H. C., and Hawkins, J. D. 1999. Positive youth development in the United States: Research findings on evaluations of positive youth development programs (NICHD Publication). Washington, DC: U.S. Department of Health and Human Services.

Catalano, R. F., Berglund, M. L., Ryan, J. A. M., Pollard, R. A., Lonczak, H. S., and Hawkins, J. D. 2004. Positive youth development in the United States: Research findings on evaluations of positive youth development programs. The Annals of the American Academy of Political and Social Science, 591, 98-124.

Center for Mental Health in Schools at UCLA. 2008. Social and interpersonal problems related to school Aged youth. Retrieved on $30^{\text {th }}$ March 2011 from: http://smhp.psych.ucla.edu/pdfdocs/socialProblems/socialprobs.pdf

Centre for Substance Abuse Prevention. 1999. SAMHSA's Center for Substance Abuse Prevention EvidenceBased Strategies Program. Retrieved on $30^{\text {th }}$ March 2011 from: http://prevention.samhsa.gov/implementation/default.aspx

Chang, L., Lei, L., Li, K. K., Liu, H., Guo, B., Wang, Y., and Fung, K. Y. 2005. Peer acceptance and selfperceptions of verbal and behavioural aggression and social withdrawal. International Journal of Behavioral Development, 29, 48-57.

Chen, X. Y., Cen, G. Z., Li, D., and He, Y. F. 2005. Social functioning and adjustment in Chinese children: The imprint of historical time. Child Development, 76, 182-195.

Chen, X. Y., Liu, M. W., Rubin, K. H., Cen, G. Z., Gao, X. P., and Li, D. 2002. Sociability and prosocial orientation as predictors of youth adjustment: A seven-year longitudinal study in a Chinese sample. International Journal of Behavioral Development, 26, 128-136.

Cohen, J. 1999. Educating minds and hearts: Social emotional learning and the passage into adolescence. New York, NY: Teachers College Press.

Collaborative for Academic Social and Emotional Learning (CASEL). 2003. Safe and sound: An educational leader's guide to evidence-based social and emotional learning (SEL) program. Chicago, IL: Collaborative for Academic, Social and Emotional Learning.

Curriculum Development Council 2001. Learning to Learn: The way forward in curriculum development. 
Hong Kong: Government Printer.

DeAngelis, T. (2010). Social awareness + Emotional skills = Successful kids. Monitor on Psychology, 41, 46 49.

Department for Education, United Kingdoms 2005 Social and Emotional Aspects of Learning (S.E.A.L.): Retrieved on $30^{\text {th }}$ May 2011 from:

http://nationalstrategies.standards.dcsf.gov.uk/inclusion/behaviourattendanceandseal.

Diekstra, R. 2008a Effectiveness of school-based social and emotional education programmes worldwide.part one, a review of meta-analytic literature. In Fundacion Marcelino Botin Social and emotional Education: an international analysis (pp. 255-284). Santander: Fundacion Marcelino Botin.

Diekstra, R. 2008b Effectiveness of school-based social and emotional education programmes worldwide.part two, teaching social and emotional skills worldwide, A meta-analytic review of effectiveness In Fundacion Marcelino Botin Social and emotional education: an international analysis (pp. 285-312). Santander: Fundacion Marcelino Botin.

Duong, M. T., Schwartz, D., Chang, L., Kelly, B. M., and Tom, S. R. 2009. Associations between maternal physical discipline and peer victimization among Hong Kong Chinese children: The moderating role of child aggression. Journal of Abnormal Child Psychology, 37, 957-966.

Durlak, J. A., Weissberg, R. P., Dymnicki, A. B., Taylor, R. D., and Schellinger, K. 2011. The impact of enhancing students' social and emotional learning: A meta-analysis of school-based universal interventions. Child Development, 82, 405-432.

Education Commission. 2000. Learning for life, learning through life: Reform proposals for the education system in Hong Kong. Hong Kong: Government Printer.

Eisenberg, N., Ma, Y., Chang, L., Zhou, Q., West, S. G., and Aiken, L. 2007. Relations of effortful control, reactive undercontrol and anger to Chinese children's adjustment. Developmental and psychopathology, 19, 385-409.

Elias, M. J., Bruene-Butler, L., Blum, L., and Schuyler, T. 1997. How to launch a social \& emotional learning program. Educational Leadership, 54, 15-19.

Gardner, H. E. 1993. Multiple intelligences: The theory in practice, a reader. New York: Basic Books.

Goleman, D. 1995. Emotional intelligence: Why it can matter more than IQ. London: Bloomsbury.

Gottman, J. M., and DeClaire, J. 1998. Raising an emotionally intelligent child. New York: Simon \& Schuster.

Green, J., Howes, F., Waters, E., Maher, E. and Oberklaid, F. 2005. Promoting the social and emotional health of primary school aged children: reviewing the evidence base for school based interventions. International Journal of Mental Health Promotion, 7, 3, 30-36.

Greenberg, M. T., Domitrovich, C., and Bumbarger, B. 2001. The prevention of mental disorders in schoolaged children: current state of the field. Prevention and Treatment, 4, Article 1. 
Greenberg, M. T., and Kusché, C. A. 1993. Promoting social and emotional children: The PATHS project. Seattle, WA: University of Washington Press.

Greenberg, M. T., and Kusché, C. A. 1996. Promoting social and emotional development in deaf children: The PATHS project: Final report to the National Institute of Mental Health, Grant No. ROIMH42131.

Greenberg, M. T., and Kusché, C. A. 1997. Improving children's emotion regulation and social competence: The effects of the PATHS Curriculum. Paper presented at the meeting of the Society for Research in Child Development, Washington, DC.

Greenberg, M. T., Kusché, C. A., and Speltz, M. 1991. Emotional regulation, self-control, and psychopathology: The role of relationships in early childhood. In D.Cicchetti, D. and S.Toth (Eds.), Internalizing and externalizing expressions of dysfunction. Rochester Symposium on Developmental Psychopathology, Vol. 2. (pp. 21-55). Hillsdale, NJ, England: Lawrence Erlbaum Associates, Inc.

Greenberg, M. T., Weissberg, R. P., O'Brien, M. U., Zins, J. E., Fredericks, L., Resnik, H., and Elias, M. J. 2003. Enhancing school-based prevention and youth development through coordinated social, emotional, and academic learning. American Psychologist, 58, 466-474.

Ho, D. Y. F. 1991. Cognitive socialization in Confucian heritage cultures. Paper presented at Workshop on Continuities and Discountinuities in the Cognitive Socialization of Minority Children, U.S. Department of Health and Human Services, Washington, DC.

Kam, C.-M., Greenberg, M. T., and Walls, C. T. 2003. Examining the role of implementation quality in school-based prevention using the PATHS curriculum. Prevention Science, 4, 55-63.

Kumpfer, K. L., Alvarado, R., Smith, P., and Bellamy, N. 2002. Cultural sensitivity and adaptation in family-based prevention interventions. Prevention Science, 3, 241-246.

Lai, K. Y. C. 2000. Primary prevention in child and adolescent psychiatry. Hong Kong Journal of Psychiatry, $10,37-42$.

Leung, P. W. L., Hung, S.-F., Ho, T.-p., Lee, C.-c., Liu, W.-s., Tang, C.-p., and Kwong, S.-1. 2008. Prevalnce of DSM-IV disorders in Chinese adolescents and the effects of an impairment criterion. European Child \& Adolescent Psychiatry, 17, 452-461.

Marcelion-Botin-Foundation. 2008. Social and emotional education: An international analysis. Effectiveness of school-based social and emotional education programmes worldwide. Santander: Fundacion Marcelino Botin.

Ministry of Education, Singapore 2010. Social and emotional learning. Retrieved on $30^{\text {th }}$ March 2011 from http://www.moe.gov.sg/education/programmes/social-emotional-learning/.

Payne, A. A., Gottfredson, D. C., and Gottfredson, G. D. 2006. School predictors of the intensity of implementation of school-based prevention programs: Results from a national study. Prevention Science, 7, 225-237. 
Payton, J. W., Wardlaw, D. M., Graczyk, P. A., Bloodworth, M. R., Tompsett, C. J., and Weissberg, R. P. 2000. Social and emotional learning: A framework for promoting mental health and reducing risk behavior in children and youth. Journal of School Health, 70, 179.

Payton, J. W., Weissberg, R. P., Durlak, J. A., Dymnicki, A. B., Taylor, R. D., Schellinger, K. B., and Pachan, M. 2008. The positive impact of social and emotional learning for kindergarten to eighth-grade students: Findings from three scientific reviews. Chicago, IL: Collaborative for Academic, Social and Emotional Learning.

Penn State Prevention Research Center 2010. PATHS (Providing Alternative Thinking Strategies). Retrieved on $30^{\text {th }}$ March 2011 from http://prevention.psu.edu/projects/PATHS.html

Schultz, D., Izard, C. E., Ackerman, B. P., and Youngstrom, E. A. 2001. Emotion knowledge in economically disadvantaged children: Self-regulatory antecedents and relations to social difficulties and withdrawal. Developmental and psychopathology, 13, 53-67.

Shucksmith, J., Summerbell, C., Jones, S., and Whittaker, V. 2007. Mental Wellbeing of Children in Primary Education (targeted/indicated activities). London: National Institute of Clinical Excellence

Sun, R. C. F., and Shek, D. T. L. 2010. Life satisfaction, positive youth development, and problem behaviour among chinese adolescents in Hong Kong. Social Indicators Research, 95, 455-474.

Tennant, R., Goens, C., Barlow, J., Day., C., and Stewart-Brown, S. 2007. A systematic review of reviews of interventions to promote mental health and prevent mental health problems in children and young people. Journal of Public Mental Health, 6, 1, 25-33.

Tsai, J. L., Chentsova-Dutton, Y., Freire-Bebeau, L., and Przymus, D. E. 2002. Emotional expression and physiology in European Americans and among Americans. Emotion, 2, 380-397.

Weare, K. 2004. Developing the Emotionally Literate School. London: Paul Chapman Publishing.

Weare, K. 2010. Mental health and social and emotional learning: evidence, principles, tensions, balances. Advances in School Mental Health Promotion. 3, 1, 5- 17.

Weare, K., and Gray, G. 2003. What works in developing children's emotional and social competence and wellbeing? Birmingham, UK: University of Birmingham, Department for Education and Skills.

Yik, M. 2010. How unique is Chinese emotion? In M. H. Bond (ed.) The Oxford handbook of Chinese psychology. New York, NY: Oxford University Press.

Zhou, Q., Eisenberg, N., Wang, Y., and Reiser, M. 2004. Chinese children's effortful control and dispositional anger/frustration: Relations to parenting styles and children's social functioning. Developmental Psychology, 40, 352-366.

Zins, J. E. 2001. Examining opportunities and challenges for school-based prevention and promotion: Social and emotional learning as an exemplar. Journal of Primary Prevention, 21, 441.

Zins, J. E., Bloodworth, M. R., Weissberg, R. P., and Walberg, H. J. 2007. The scientific base linking social and emotional learning to school success. Journal of Educational and Psychological Consultation, 
$17,191-210$

Zins, J. E., and Elias, M. E. 2006. Social emotional learning: Promoting the development of all students. In G.

G. Bear \& K. M. Minke (Eds.), Children's Needs III: Development, Prevention and Intervention (pp. 1-13). Washington, DC.: National Assocation of School Psychologists.

Zins, J. E., Weissberg, R. P., Wang, M. C., and Walberg, H. J. 2001. Social-emotional learning and school success maximizing children's potential by integrating thinking, feeling, behavior. The CEIC (Center on Education in the Inner Cities) Review, 10, 1-9.

Zins, J. E., Weissberg, R. P., Wang, M. C., and Walberg, H. J. 2004. Building academic success on social and emotional learning: What does the research say? New York: Teachers College Press. 